\title{
La antropología literaria: lenguaje intercultural de las ciencias humanas
}

\author{
Literary Anthropology: Intercultural language of the human sciences
}

\author{
Solange Cárcamo Landero
}

Universidad Católica de Temuco, Casilla 15- D, Temuco, Chile.

Estudiante Doctorado en Ciencias Humanas UACh

e-mail: scarcamo@uct.cl

\begin{abstract}
Este artículo presenta un análisis y reflexión sobre las posibilidades y límites de la antropología literaria como redescripción de las ciencias humanas en contextos de diversidad cultural. Para ello, se articula una reflexión en torno a tres grandes temas: la relación entre cuerpo y lenguaje, la construcción de una mirada interdisciplinaria y el encuentro entre culturas. Se postula que la forma de escritura expresiva, transgresora y sugerente que constituye a la antropología literaria es, simultáneamente, un lenguaje nuevo y un metadiscurso humanista de las ciencias humanas. La estrecha relación entre el oficio de escritor y de investigador social/científico social, que ella propone como ineludiblemente necesaria para dar cuenta de la riqueza/diversidad de la vida cotidiana, abriría una vía para superar la amalgama de subjetivismo y objetivismo que prevalece en las ciencias sociales.
\end{abstract}

Palabras clave: antropología literaria, ciencias humanas, interculturalidad, cuerpo interpretante.

This article presents an analysis and reflection on the possibilities and limits of literary anthropology as a restatement of the human sciences in contexts of cultural diversity. For this purpose, a reflection around three great subjects is presented: the relationship between body and language, the construction of an interdisciplinary look, and the relationship between cultures. It is claimed that the form of suggestive, transgressing and expressive writing that constitutes literary anthropology is both a new language and a humanistic metadiscourse of the human sciences. The narrow relationship between the work of a writer and that of a social researcher or social scientist proposed, as inescapably necessary, is just to give an account of the richness or diversity of daily life. This would open a way in order to overcome the amalgam of subjectivism and objectivism prevailing in the social sciences.

Key words: literary anthropology, human sciences, cross-cultural, interpretant body.

\section{INTRODUCCIÓN}

La articulación entre literatura y antropología, así como también entre literatura y otras ciencias humanas, no es nueva ${ }^{1}$. Sin embargo, en la actualidad, las ciencias sociales empírico-analíticas generalmente olvidan la necesidad de establecer vasos comunicantes con la literatura y, por el contrario, buscan separarse del mundo literario y competir con él ${ }^{2}$. Superar este olvido pasaría por reconocer el potencial que tiene esta relación interdisciplinaria para dar cuenta de la riqueza y diversidad de la vida humana $^{3}$. Específicamente el diálogo contemporáneo entre antropología y literatura revela una dialéctica entre ambos quehaceres, proceso mediante la cual el antropólogo deviene en escritor y el escritor en antropólogo, lo cual daría lugar a un objetivo compartido: “...la búsqueda y la creación del sentido a

\footnotetext{
${ }^{1}$ Específicamente, con respecto a la relación entre literatura y antropología en América Latina, López- Baralt, M. (2005) nos ofrece una completa síntesis interpretativa de la ambición etnográfica de nuestras letras y de la antropología como literatura. Asimismo, cabe señalar algunos comentarios que al respecto ha formulado J.J. Brunner: “...en sus orígenes la sociología apenas lograba distinguirse de otros géneros, entendidos éstos como universos ideológico-verbales diferenciados entre sí. Así, por ejemplo, hasta muy tarde -entrado ya el siglo XIX-su discurso se mantuvo entremezclado dentro del campo semántico de la filosofía, la historia, la literatura y el ensayo. Sólo con el tiempo llegó a constituir un lenguaje separado, relativo, objetual y limitado a una profesión intelectual" (Brunner 1997:1).

2 Al respecto, Pedro Morandé señala: "La disputa entre el modo literario y el empírico tradicional de la antropología no sólo afecta a esta disciplina, sino prácticamente a todas las ciencias sociales" (2006).

${ }^{3}$ En este sentido, J. J. Brunner compara a la teoría sociológica con la novela, su eterna competidora, señalando que esta última aventaja ampliamente a la primera desde el punto de vista de la calidad y riqueza de los saberes que genera. Para Brunner la sociología sería: “...un lenguaje que, después de sus clásicos y epígonos, al parecer no tiene mucho que decir al mundo (...) puede ser, efectivamente, que el lenguaje de la sociología haya dejado de hablar. Ni sus grandes categorías sistemáticas, ni sus pequeños conceptos de interpretación de la vida cotidiana, parecen sostenerse en pie frente al doble embate del Banco Mundial y la novela contemporánea (...) ésta representa más ricamente que la sociología los elementos de la vida interior y colectiva” (1997: 1-3).
} 
través de la palabra" (López-Baralt 2005:59). Precisamente, el vínculo que se establece desde la antropología hacia la literatura es el que interesa desarrollar en estas páginas; si bien sabemos que la interacción entre ambas disciplinas es recíproca. De hecho, al respecto podemos enfatizar que las conversaciones que estas disciplinas han establecido a través de la historia revelan la preocupación por un problema, común y fundamental, que gira en torno a la pregunta: “¿es posible escribir sobre el Otro sin destruirlo?" (Id. 30).

Justamente, esta interrogante expresa el problema de un tipo de escritura descontextualizada que prevalece en las ciencias humanas, escritura sobre -y no escritura desde- que lleva a uniformar la existencia humana, ocultando su diversidad.

Una versión actual y novedosa de esta articulación disciplinaria la encontramos en la antropología literaria que es y contiene una forma de escritura transgresora; escritura que se desarrolla desde el cuerpo, desde las fronteras internas y externas, desde lo ambiguo y diverso. Considerando esta perspectiva, en este artículo se busca rescatar la posibilidad de una caracterización de la antropología literaria como redescripción de las ciencias sociales en un contexto de conflictividad intercultural. Para ello se desarrolla una reflexión sobre esta forma de escritura nueva en Chile y su capacidad de rearticular el lenguaje de las humanidades y las ciencias humanas. En este sentido, se formulan algunas interrogantes relacionadas con su potencial para superar la violencia simbólica que se ejerce con una práctica dogmática de la epistemología: práctica que conlleva el no reconocimiento de la alteridad.

De este modo, el trabajo interpretativo que se plasma en estas páginas busca vislumbrar los aportes y dificultades de la antropología literaria como medio para superar, desde las humanidades, el problema de la incomunicación entre culturas; todo ello en el horizonte de la comprensión y el reconocimiento de la diversidad $^{4}$. Para ello, se desarrolla una interpretación crítica de un conjunto de estudios reunidos en el libro: El Espejo Rápido. Interculturalidad y prevaricaciones discursivas, del antropólogo y ensayista chileno Miguel Alvarado Borgoño. Esta interpretación se realiza en diálogo con algunas aportaciones bibliográficas de autores preocupados del estudio de la trilogía: literatura, interculturalidad y prácticas interdisciplinarias, especialmente: Carrasco, I. (1972) y López-Baralt, M. (2005), FornetBetancourt, R. (2002), Mignolo, W. (1998). Este diálogo también sintoniza con la lectura que realizan autores como Paredes (1999) y Verano (2000) sobre la relación cuerpo, lenguaje y sociedad; lecturas elaboradas partir de las investigaciones desarrolladas por Merleau-Ponty.

Específicamente, la metodología de este trabajo consiste en buscar en el texto mismo de El Espejo rápido tanto las maneras de autodefinirse como antropología literaria, como las estrategias discursivas más relevantes que adopta para superar las formas convencionales de narración que existen en las ciencias sociales. Además, en dicho texto, se busca alguna señal que indique el tipo de diálogo que la antropología literaria pretende establecer con las demás ciencias sociales para alcanzar reconocimiento como "una teoría antropología que haga suyas las herramientas narrativas y poéticas de la literatura" y que, por lo tanto, no sea sólo considerada como "mera narración etnográfica de corte poético" 5 .

\section{2. “PARA DECIR AL OTRO”: LO QUE ENTENDEMOS POR ANTROPOLOGÍA LITERARIA}

Las palabras encarnadas de un estudioso de las humanidades surgirían cuando él se piensa y se siente un autor fronterizo y que, como tal, sabe que se encuentra en una situación semejante a la del Coronelde

\footnotetext{
${ }^{4}$ Un análisis profundo de las implicancias del concepto de reconocimiento, tanto en la vida privada como pública, lo aporta Charles Taylor con sus diversos escritos sobre el tema: "Si queremos comprender la íntima conexión que existe entre la identidad y el reconocimiento tendremos que tomar en cuenta un rasgo decisivo de la condición humana que se ha vuelto casi invisible por la tendencia abrumadoramente monológica de la corriente principal de la filosofía moderna (...) Este rasgo decisivo de la vida humana es su carácter fundamentalmente dialógico. Nos transformamos en agentes humanos plenos, capaces de comprendernos a nosotros mismos y por tanto de definir nuestra identidad por medio de nuestra adquisición de enriquecedores lenguajes humanos para expresarnos (...) Las personas, por sí mismas, no adquieren los lenguajes necesarios para su autodefinición (...) el que yo descubra mi propia identidad no significa que yo la haya elaborado en el aislamiento, sino que la he negociado por medio del diálogo, en parte abierto, en parte interno, con los demás”. (Taylor 1993: 5-6). Al respecto, véase también: Taylor, Ch. 1994. La ética de la autenticidad. Barcelona: Paidós.

${ }^{5}$ Con respecto al sentido de la antropología literaria y su definición, Alvarado señala explícitamente: “...el concepto de poesía presente en las obras de esta antropología no es una categoría poética en el sentido literario del concepto, sino una categoría de carácter teórico-metodológico definida epistemológicamente desde una concepción 'interpretativa', crítica de la racionalidad y de la textualidad científica, al estilo de la antropología postmoderna... 'Hacerse' antropólogo-poeta es practicar la antropología desde una autorreferencia que epistemológicamente significa el desplazamiento de la centralidad de esta práctica desde lo observado hacia el propio observador" (2006: 370-371).
} 
García Márquez: "el antropólogo literato no tiene quién le escriba"6. Se imagina y crea, entonces, a unos lectores-cómplices ideales a quienes les escribe misivas fronterizas y de quienes recibe una crítica complicidad que potencia su deseo de transgresión de los límites disciplinarios de las ciencias sociales. Esto es lo que sucede con El espejo rápido de Miguel Alvarado. Ya en su libro El sueño de la comunicación $n^{7}$, Alvarado comienza a dibujar la existencia de un híbrido, un "engendro", dirían algunos cientistas sociales convencionales. Mas, si nos situamos en las Humanidades, entendiendo a éstas no como el acopio o acumulación de materias y métodos científicos, sino más bien como una praxis de autoformación, es decir, como un proceso "en virtud del cual uno aprende a mirar más allá de su propia peculiaridad" (Grondin 2003:48) ${ }^{8}$; se comienza a percibir que el engendro, ya entonces, nos hablaba confrontacionalmente sobre lo insuficiente, superficial y plano que resulta la lectura de lo social cuando ésta se realiza a partir de descripciones basadas en una concepción de la escritura que entiende el lenguaje como algo puramente designativo?.

El engendro, en definitiva, es lo que estamos vislumbrando como antropología literaria. Y verdaderamente nos parece una identidad monstruosa, una especie similar al monstruo de Frankenstein de Mary W. Shelley que asusta porque aparece como una mentira que cuenta la verdad. Pero, simultáneamente, advertimos, como en la novela de Frankenstein, que el monstruo es, incluso, más humano que su creador, ya que reacciona como tal en todas y cada una de las ocasiones, con un lenguaje abiertamente transgresor para satisfacer su necesidad de reconocimiento. En este sentido, la antropología literaria estaría ejerciendo su libertad y ahora pide explicaciones a su creador: está exigiendo participar en un espacio público, demanda su reconocimiento. La "criatura" se enfrenta a su creador: La antropología literaria quiere ser reconocida como un lenguaje nuevo en las ciencias humanas, capaz de desarrollar unas ciencias expresivas ${ }^{10}$. $\mathrm{O}$, tal vez, desea ser inscrita como metadiscurso humanista de las ciencias humanas. Cabe, precisar, entonces, que no es el lenguaje transgresor ni la amalgama de géneros discursivos lo que identificaría como "monstruosa" a esta forma de escritura, sino la falta misma de reconocimiento; nuestra incapacidad para apreciar el sentido oculto de lo diverso dentro de lo diverso; nuestra miopía para vislumbrar el potencial de la alteridad. En otros términos, es la identidad "monstruosa", adscrita por otros a la antropología literaria, es el rechazo a su deseo de ser-otraescritura, a ser la alteridad-radical-escrita desde el mundo de las ciencias humanas y humanidades (lo cual es diferente a ser-otra(o) como yo: a ser otra escritura como la mía). Todo esto es lo que finalmente la convierte en monstruosa, para algunos.

Pese a estas resistencias, sutilmente, el monstruo de la antropología literaria comienza a aceptarse para reconocerse; empieza a tener un discurso sobre sí mismo que es el primer paso para ser libremente, "Sin pena ni miedo" (como diría Zurita) y poder entrar así en la lucha por el reconocimiento de su identidad como texto genuino de las humanidades en nuestra América. De hecho, si analizamos la carta de Sonia Montecino, al comienzo del libro, podemos encontrar una serie de adjetivaciones polisémicas sobre la antropología literaria, que revelan ellas mismas el ethos expresivo de esta forma de escritura. De hecho se refiere a ella diciendo:

\footnotetext{
${ }^{6}$ La novela El coronel no tiene quién le escriba de Gabriel García Márquez (1957) permite comprender la vivencia angustiante y contradictoria de quien desea mantener "un resto de dignidad"/reconocimieto en un contexto de injusticia social.

${ }^{7}$ En la introducción de este libro, su autor nos habla de proponer otras preguntas sobre las posibilidades y límites de la narración en ciencias humanas. Al respecto, nos dice: "Si la tarea de las ciencias de la cultura es narrar lo diverso, el sueño de la comunicación, y la angustia de no darse a entender y de no ser entendido, se convierte en un hecho cada vez más creíble (...) las posibilidades de narrar son limitadas y el sueño de la comunicación se transforma en una pregunta (...) el concepto hecho tipo ideal no da certidumbre sino vacío, y en eso resulta nuestro discurso científico social: en un inmenso vacío, que se manifiesta fértil cuando se llena con los anhelos del científico por hablar del otro, espejo de nuestros anhelos" (Alvarado 2004: 18-19).

${ }^{8}$ En este mismo sentido, Grondin nos señala que: "La persona culta no es aquella que sabe hacer ostentación de un deslumbrante saber de formación cultural. El que se comporte así no es culto, sino que es un pedante. [...] Conceder vigencia a las ideas de otra persona, en eso consiste la verdadera cultura y formación, porque presupone elevarse sobre la propia limitación. Por consiguiente, la formación no se realiza por el camino del querer saberlo todo, sino por el saber que hay cosas que uno no sabe" (2003: 49).

9 En sus estudios sobre el lenguaje y la naturaleza humana, Taylor (2005) nos explica que desde una perspectiva designativa del lenguaje, el significado de las palabras o las frases se entienden teniendo como base o supuesto la relación con las cosas o el estado de ellas en el mundo. El lenguaje sólo tiene una función ordenadora e instrumental con respecto al pensamiento y los sentimientos, otorgando un papel central a la designación: se explica un signo o una palabra con significado apuntando a la cosa del mundo a la cual se puede hacer referencia con ese signo o esa palabra y a lo que somos capaces de decir con éstos sobre ella.
}

${ }^{10}$ El concepto de expresión se asume aquí de acuerdo a la interpretación que establece Taylor, para quien el aspecto expresivo vuelve manifiesta una cosa al encarnarla. Aquí el término "manifiesto" es fundamental y debe considerarse en sentido fuerte. La expresión no consiste en inferir algo que no veo directamente, sino que, por el contrario, hace manifiesto algo, lo hace presente, lo encarna. De este modo, "lo que manifiesta la expresión sólo puede manifestarse en la expresión" (Taylor 2005: 39). 
... esa 'antropología que soñamos', cuyo eje [...] es el 'lenguaje al servicio de la utopía'... ese género textual 'híbrido y original' que emerge en nuestro país... programa de una antropología que hable de tres ciclos: el de la naturaleza, del capitalismo y el del deseo... incipientes trazos de una antropología literaria chilena. (Cit. en Alvarado 2006: 14-15).

Asimismo, con su carta, Montecino se inscribe dentro de esta forma de escritura que para ella, necesariamente, implica "hablar, escribir y leer de acuerdo a (la) propia biografía" (Id. 15). Dice, además: “...es otra forma de expresar el "peso del cuerpo" en el campo de la interpretación... los cuerpos marcan no sólo nuestra escritura sino la recepción de la misma" (Id. 15). En este punto, habla de la antropología literaria como experiencia de una escritura que es "carne": un lenguaje, unas palabras, que son la prolongación de su cuerpo; a través de lo cual ha vivido "las discriminaciones disciplinarias por una creatividad que intersecta género, antropología y literatura, por una voluntad colectiva y femenina de subvertir los órdenes y que nació en la dictadura como clara resistencia al poder de la muerte inscrita en el modelo" (Id. 2006: 15).

De este modo, para Montecino la antropología literaria sería una escritura de "resilencia", pero "desafiante" y "atrevida", elaborada desde un cuerpo vivido, "desde un cuerpo histórico y deseante" (Ibíd. 2006: 15); consciente, además, de los obstáculos que conlleva la obsesión de algunos por los límites disciplinarios en ciencias humanas. En cuanto a este último aspecto, se refiere a la antropología literaria de Alvarado como posibilidad de un despliegue de la antropología "hacia otros campos y otros espacios discursivos... otra forma de engarzar, cruzar y mestizar géneros en el camino de resignificar el campo de nuestra disciplina" ( Ibíd. 2006: 15).

En el prólogo de El espejo rápido, Zurita también nos aporta unas claves para ir comprendiendo qué es la antropología literaria. Se refiere a ella como el despliegue de una lucidez que se alcanza sólo en el clímax de la desesperación: “... la tensión y el desgarramiento...cruza cada párrafo, cada palabra, cada referencia..." (Cit. en Alvarado 2006: 18). Para Zurita este libro, esta forma de escritura, es en sí la metáfora de "una identidad que permanentemente se erosiona", que "se vuelve sentido", "se transforma en cultura", se vuelve "una sustancial alteridad". Se trataría también de una "propuesta de vislumbre", una "pesquisa apasionante". Al mismo tiempo nos dice que: "Es una escritura sobre la escritura misma, empeñada en narrar la narración sobre la alteridad" (Id. 2006: 17).

Para Zurita las referencias a conceptos, teorías y definiciones que Alvarado elige para escribir este libro como antropólogo-literato constituyen un discurso sincrético para expresar el dramatismo fundamental que encierra el reconocimiento de la extrañeza del otro, que es siempre el comienzo de la vivencia de la extrañeza interior. Esta vivencia del otro y de uno mismo como un ser inaccesible, lo invade todo, todas las creaciones humanas, por ejemplo, la historia de la antropología o el problema epistemológico de la narración; y entonces, el drama se transforma en "deseo": deseo de existir "sólo en el silencio", "deseo de ser sólo un vacío"11.

Zurita también habla de que en la antropología literaria de Alvarado habría una apelación ética: Desde la vivencia de la extrañeza del otro, vivenciada como una pérdida, surge el deseo de pertenencia y la necesidad de levantar una comunidad, es decir, un compromiso. Desde esta perspectiva ética, para Zurita, la antropología literaria sería el rito de escribir para exorcizar con "las mismas palabras viejas", "manías cruentas e impredecibles" (Id. 19). Esas "palabras viejas" se vuelven sugerentes y hasta liberadoras porque cambia la actitud de quien escribe. Este cambio de actitud ocurre porque, el antropólogo literato, representado, para Zurita, en Miguel Alvarado, sabe que “... todo nos separa del otro, y sin embargo, desde esa fisura... desde esa separación insalvable, es desde donde debemos levantar una ética del perdón..." (Id. 19). La crítica radical a toda construcción humana se convierte en la antropología literaria en autocrítica, porque se asume la idea de que somos-en-el-mundo, en el mundo que es "ese otro que desde siempre somos todos": somos-en-el-otro.

Pues bien, si esta es la visión que Montecino y Zurita (dos de sus "lectores cómplices ideales") tienen de la antropología literaria desarrollada por Alvarado, nos interesa saber ahora cómo Alvarado

\footnotetext{
${ }^{11}$ La antropología literaria de Alvarado sería, además, para Zurita, un discurso sobre la construcción del otro en Nuestra América desde las humanidades, propuesta que "no puede dejar de contextualizarse dentro de la trama que abrió la antropología experimental latinoamericana surgida en la década de los sesenta y radicalizada en las dictaduras de los setenta" (Cit. en Alvarado 2006: 18). Este discurso sobre la construcción del otro que hace la antropología literaria se desarrollaría desde la narración del sufrimiento que se confronta con el sufrimiento colectivo, con una comunidad herida y desde este punto llega a vislumbrar "la posibilidad de un amor o de un abrazo que surge sólo desde el momento en que nos damos cuenta que el otro es mi espejeante modo de entenderme con el mundo" (Id. 18). El antropólogo literato sabe que: "Lo estudiado nos estudia, nos relata, y al intentar describirlo nos damos cuenta de que hemos sido descritos" (Id. 19).
} 
autointerpreta este concepto de escritura al cual se adscribe y desde el cual se autodefine como escritor y ensayista de las ciencias humanas.

Alvarado inscribe su antropología literaria como un programa científico en ciencias humanas, el cual, dice: "es inevitablemente un proyecto escritural, y sus éxitos paradigmáticos más bien se corresponden con su capacidad seductiva (al estilo del ritual que envuelve), y no con su capacidad de acumular verdad(es)" (Alvarado 2006: 369).

En este sentido, asume también el concepto de escritura de Barthes y con él afirma que su escritura es "un acto de solidaridad histórica" (Id. 368), la realizan personas que están vivas, comprometidas con su práctica social $y$ con sus formas escriturales. Asimismo, Alvarado continúa explicando que, en este proyecto escritural, lo realmente profundo es el "lenguaje mismo", el "imperio del significante". Al respecto, dice que el sustento de la antropología literaria es la premisa de: “... que el lenguaje en su dialéctica texto-contexto es constructor de mundo" (Id. 369). Sin embargo, esclarece que personalmente prefiere asumir al lenguaje como constructor de ideología para dar cuenta del "deambular del sentido" (Id. 369). Por ello nos dice:

... se nos hace necesario un concepto de antropología literaria con el cual reelaborar el mito, y de esa manera seguir en el camino que el lenguaje abre como una suerte de Moisés que separa las aguas de la incomunicación, liberada nuestra lengua del vacío que genera la falta de isomorfía o equivalencia entre texto etnográfico y mundo sensible (Alvarado 2006: 374).

Podría decirse también que la antropología literaria es no sólo antropología poética, sino que acogiendo y asumiendo el aporte de ésta, en cuanto "narración mimética en el sentido de cocreación creativa de la realidad" (Id. 370), pretende encaminarse hacia una argumentación y reflexión teórica de lo social; en donde la literatura no es sólo una estrategia metodológica, sino una dimensión constituyente de unas ciencias humanas expresivas, que vienen a transformar el discurso científico porque ya no tiene sentido la separación entre lenguaje/pensamiento sobre el mundo y lenguaje/pensamiento desde el mundo.

La estrategia narrativa de la antropología literaria desarrollada por Alvarado sería la de un ensayo que constituye una articulación entre filosófica del lenguaje y hermenéutica, epistemología en "Nuestra América" y el aporte de la teoría literaria y la literatura. Articulación plasmada en el itinerario del texto mismo como irrupciones de metáforas y referencias poéticas que a momentos aparecen como una sutil infiltración y, en otros, como asalto violento a nuestra lectura. Todo ello, finalmente, termina transformando el contenido del libro, con lo cual podemos afirmar que esta forma escritural no sólo define el contenido, sino que es el contenido. En suma, la estrategia narrativa de la antropología literaria sería lo que Alvarado define como etnografía del texto, esto es: “...un acceso interdisciplinario a los diversos tipos de textualidad que en una cultura se generan", "La narración del encuentro con la materialidad de lo amado, objetos, lugares, personas" (Id. 199 y 100).

Con estas aseveraciones, el autor nos estaría diciendo que la escritura de la antropología literaria está abierta al lector y que requiere una lectura interpretativa: el que lee no debe buscar en el discurso del antropólogo literato alguna verdad cerrada, una conclusión, sino más bien acoger aquellos elementos del texto que le resulten sugerentes, ya que articulan su pensar y su sentir más auténtico (del lector). Desde esta perspectiva, la antropología literaria sería, además, una invitación a comprometerse con la lectura que se está haciendo, como cuando leemos la carta desesperada de un amigo y sentimos que debemos responderle urgente y profundamente. De hecho, el libro concluye tomando prestadas algunas palabras de Georges Bataille, las cuales nos sugieren esta idea: “...no he querido expresar mi pensamiento, sino ayudarte a extraer la indistinción de lo que tú piensas...”.

\section{UNA TRILOGÍA TEMÁTICA PARA EL RECONOCIMIENTO DE LA ANTROPOLOGÍA LITERARIA}

Los ensayos escritos y reunidos por Alvarado en El espejo rápido permiten vislumbrar tres temas que sitúan, con mayor claridad, la reflexión sobre la forma en que la antropología literaria puede ser reconocida por las ciencias sociales; especialmente, por aquellas que se desarrollan desde paradigmas científicos convencionales. En este sentido, la reflexión giraría en torno a la siguiente trilogía temática: articulación entre lenguaje y cuerpo, indisciplinamiento de las ciencias sociales y definición de lo intercultural.

La comprensión del potencial de la antropología literaria, para generar conocimiento "desde lo otro", tiene relación con la particular conexión que realiza entre lenguaje y cuerpo. Como veremos, tanto sus 
autodefiniciones como la forma de escritura que desarrolla, están marcadas por la experiencia corporal que despliega un horizonte indeterminado de significación. Como diría Merleau-Ponty, "por" el cuerpo hay mundo ${ }^{12}$. Así, en este texto de antropología literaria más que afirmar "yo tengo cuerpo", lo que se enfatiza es "yo soy cuerpo". Se trata de un cuerpo interpretante, es decir, que se interpreta a sí mismo ${ }^{13}$.

Desde esta perspectiva, las palabras estarían inscritas en el cuerpo como un modo de ser en el mundo y el lenguaje ya no sería sólo un fenómeno comunicativo, sino una experiencia comunicativa en la que se conjugan modos de ser y visiones de mundo. Entonces, la palabra es inherente al cuerpo, es una experiencia corporal, un acontecimiento. Este sentido de la palabra, que Merleau-Ponty desarrolla, se aprecia nítidamente en la forma de escritura del antropólogo-literato que, en tanto autor, vive la experiencia humana como experiencia de lenguaje: el autor siente su ser hombre o su ser mujer y lo vive como palabra hablante y no sólo como palabra hablada ${ }^{14}$. En este sentido, es el cuerpo el que habla. Se vive la experiencia de un cuerpo hablante, que es la experiencia corporal de la palabra vivenciada como invasión del sentido o del sinsentido; es, por tanto, una experiencia abierta irreductible a la conciencia humana.

Para Alvarado esta antropología literaria es una nueva forma de escritura que

tiene que considerar la materialidad del dolor no solamente propio sino también ajeno, y quizás sea el mismo cuerpo del etnógrafo, nuestros cuerpos, los que nos obliguen no sólo a poetizar, sino también a pensar en la ingenua y legítima utopía de la plenitud posible... (Id. 2006: 373).

Más adelante agrega:

¿Qué me dices, Sonia, si pensamos de qué manera la reflexión respecto del cuerpo propio y el ajeno puede ser la forma que ansiamos de aunar narración, pensamiento y poesía en el texto antropológico? [...] Las antropología(s) poética o literaria será(n) siempre unas antropología(s) del cuerpo, ditirámbica(s), inconclusa(s) o funcionalmente inútil(es), pero éticamente necesaria(s) (Id. 374).

Un segundo aspecto o ámbito temático, que nos permitiría entender la noción de antropología literaria, sería la articulación de esta forma de escritura con las denominadas "epistemologías fronterizas". Con este concepto se hace referencia a unos enfoques que construyen conocimiento desde contextos de diversidad sociocultural y que, por lo tanto, buscan indisciplinar las ciencias sociales con la finalidad de avanzar en un diálogo intercultural, tanto al interior de dichas ciencias como en el conjunto de la sociedad $^{15}$. En este sentido, para Mignolo (1998) indisciplinar las ciencias sociales significa enfatizar una epistemología fronteriza que tendría que constituirse en una reflexión filosófica, literaria y ensayística incorporada a las historias locales. Precisamente, la antropología literaria recrea esta articulación de

\footnotetext{
${ }^{12}$ La fenomenología de Merleau-Ponty ofrece una amplia y profunda perspectiva sobre la vida humana en tanto existencia encarnada. Para él, el cuerpo no es un objeto o una máquina de información, sino el centinela que asiste silenciosamente a nuestras palabras y actos. Según Paredes, el análisis que este filósofo desarrolla sobre el cuerpo-propio, "abre la posibilidad de investigar el sujeto humano como tal de un modo sustantivamente nuevo, en comparación con ciertas tendencias predominantes en la filosofía tradicional (...) desvela nuevas dimensiones del ser concreto del hombre en cuanto sujeto de conocimiento y de acción. (...) Ser sensible a los objetos es estar entre ellos y pertenecer al mundo tomando parte de él a través o gracias a mi cuerpo (...) Por estar mi yo encarnado en este cuerpo, no sólo soy capaz de implicarme en el mundo mediante actividades corporales, también, y precisamente por eso, me abro a la acción del mundo sobre mî́ (Paredes 1999: 41, 49).
}

${ }^{13}$ La concepción ontológica del cuerpo desarrollada por Merlau-Ponty se levanta como crítica a las interpretaciones que conciben el lenguaje como simple instrumento del pensamiento. "La idea del cuerpo interpretante elimina la creencia en un ser interior, llámese pensamiento, espíritu o conciencia, que tenga por función el uso del lenguaje como medio de expresar y conocer el mundo" (Verano 2000: 201).

${ }^{14}$ En su libro Fenomenología de la percepción (1975) Merleau-Ponty nos presenta estos conceptos para dar cuenta de la distinción entre un discurso auténtico (palabra hablante) y un discurso sobre discursos que da cuenta de expresiones ya acontecidas (palabra hablada). Para este fenomenólogo, entre ambos discursos existe un mutuo condicionamiento que hace posible otros actos de expresión auténtica, como los de un escritor, un artista o un filósofo. Al respecto, es necesario enfatizar el aporte de Paredes, quien a partir de esta distinción plantea que: "La comunicación lingüística es, por un lado, una comunicación intelectual cuando la palabra se apoya en un concepto previo, sin dejar nunca de ser, por otro lado, una comunicación vital e incluso corporal, cuando la palabra no traduce un pensamiento ya hecho, sino que contribuye a formarlo" (Paredes 1999: 55).

${ }^{15} \mathrm{Al}$ respecto cabe destacar que W. Mignolo entiende por epistemologías fronterizas un conocimiento crítico local que surge de la intersección entre historias locales y diseños globales. Este conocimiento crítico local, ya sea americano, africano o europeo favorecería el desarrollo de espacios para la generación de conocimiento desde los propios agentes locales y su reconocimiento, hasta ahora suprimido por un pensamiento colonialista y occidentalista. Véase: Mignolo, W. (s.f.) "Espacios geográficos y localizaciones epistemológicas: La ratio entre la localización geográfica y la subalternización de conocimientos". Disponible en: http://www.javeriana.edu.co/pensar/Rev3.html 
filosofía, literatura y conocimiento local a partir de un estilo ensayístico y epistolar; estilo que permite retener en la propia escritura las historias locales que aparecen siempre como historias de vida. Para aproximarnos a este potencial estilo articulador de reflexiones escindidas, es necesario precisar aquí qué se podría entender por indisciplinar las ciencias sociales desde la antropología literaria:

Indisciplinar las ciencias sociales es una manera de rearticular un diálogo nuevo entre ciencias sociales y humanidades, buscando con ello establecer una interlocución crítica entre las disciplinas, cuestionando su conformación misma y su relación con el capitalismo. Al respecto, Castro-Gómez señala:

La subalternización del pensar y de los conocimientos (...) no se resuelve mediante la integración de lo "otro" a la epistemología dominante (...) las formas disciplinarias mismas, sus metodologías y tecnologías de producir y representar los discursos, tienen que ser descolonizadas (...) la tarea actual es indisciplinar las ciencias sociales para acceder a nuevas formas de pensar tanto adentro como afuera de ellas (Castro-Gómez, Schiwy y Walsh 2002: $12-13)^{16}$.

En este sentido, la antropología literaria se opone tanto a la metodología como a los supuestos epistemológicos "descorporeizados" y "descontextualizados" de la actual realidad latinoamericana. Esta actitud crítica se puede apreciar, por ejemplo, cuando en El espejo rápido se rescata el concepto de "pensamiento-situado", es decir, la idea de contextualizar el pensamiento, y el autor de esta obra nos advierte que una etnografía del texto requiere asumir, necesariamente, un "enfoque hermenéutico culturalmente situado" (Alvarado 2006: 205). Rescata y reconoce, entonces, la literatura de los grupos étnicos y asume como una posibilidad, muy cercana en el tiempo, el hecho de que, por ejemplo, la producción literaria mapuche sea "un tipo de producción de conglomerados culturales con sus propios intelectuales orgánicos" (Alvarado 2006: 192). Desde esta perspectiva hermenéutica situada, la antropología literaria asume la necesidad de dialogar con las obras literarias indígenas, aquéllas creadas por hablantes nativos desde su propia lengua y cosmovisión. Esta necesidad expresaría la carencia del pensamiento occidental por captar lo diverso dentro de lo diverso; carencia que se transforma en el deseo (de la antropología literaria chilena) de comprender la capacidad que tiene, por ejemplo, el pueblo mapuche para concebir "la realidad simultáneamente en base a categorías de índole mítica e histórica de origen diverso" (Carrasco, I. 1972: 23). Esta capacidad se expresa en lo que I. Carrasco define como el rasgo constitutivo de la literatura mapuche: su heterogeneidad o hibridez estructural, lo cual implica que sus textos "presentan realidades heterogéneas que necesitan ser captadas en su complejidad esencial" $(\text { Id. } 23)^{17}$.

Continuando con la reflexión en torno a un posible indisciplinamiento de las ciencias sociales, cabe señalar que en el pensamiento de Alvarado esta postura no implicaría soslayar todas las herramientas o conocimientos de las ciencias ni la hermenéutica crítica de las humanidades. Ello se advierte, por ejemplo, cuando rescatando la lectura de Alfred Schutz sobre el Quijote y refiriéndose a ella como una etnografía del delirio, nos habla de los conceptos de comprensión y mundo de la vida en tanto "artefactos cautivantes para nuestras ciencias humanas en Sudamérica" (Alvarado 2006: 93). En este sentido, Alvarado señala que: "Schutz nos pone frente a la posibilidad de una antropología del delirio, no porque el etnógrafo deba ser un ente delirante, sino por la superposición de planos de lo real, donde el mundo deviene en una espiral de miradas" (Id. 97).

Asimismo, esta vocación de indisciplinamiento presente en la antropología de Alvarado se sabe contextual y no contextualista y entonces no se cierra y, por ello rescata, también, los conceptos de descripción densa y de perspectiva desarrollados por el antropólogo norteamericano Cliford Geertz, recientemente fallecido ${ }^{18}$. Y sólo para señalar un ejemplo más que ilustra la vocación de la antropología literaria por indisciplinar las ciencias sociales, con lo cual se orientaría hacia una auténtica y genuina

\footnotetext{
${ }^{16}$ Estos autores continúan explicando que indisciplinar significa evidenciar el disciplinamiento, las formas disciplinarias que se construyen en las ciencias sociales, enfatizando su legado colonial. Hablan entonces, del "poder disciplinario de Foucault, un poder que no sólo castiga sino premia, un poder que trabaja sobre los transgresores desde adentro, consolidando las filas de lo "normal'" (Castro-Gómez, Schiwy y Walsh 2002: 13).

${ }^{17}$ Cabe señalar que Alvarado asume esta postura haciendo suyas las palabras de Iván Carrasco respecto a la literatura mapuche. " Una de las características fundamentales de la literatura mapuche es su heterogeneidad o hibridez estructural, es decir, la capacidad que poseen los diversos elementos que conforman la estructura de gran parte de sus textos literarios de aportar varias significaciones simultáneas que no se excluyen mutuamente, sino se integran en unidades significativas multifacéticas con predominio de lo dual. En otras palabras, cada elemento no designa unívocamente a un solo aspecto de la realidad, sino en forma simultánea a dos o más"” (Carrasco 1972: 22).

18 De hecho, cuando escribe el capítulo "Elogio del sincretismo" no deja de señalar la importante influencia de este antropólogo en el pensamiento del teólogo y antropólogo peruano Manuel Marzal (Alvarado 2006: 125-128).
} 
interdisciplinariedad, podemos ver cómo Alvarado busca en el pensamiento de Pierre Bourdieu, un teórico interdisciplinario que habla de la Miseria del mundo, los conceptos que este autor "aporta a una teoría de la narración de la diversidad, un instrumento analítico que libere, al menos parcialmente, de los límites del tipo ideal como modelo rígido" (2006: 104). Así valora, entre otros, el concepto de habitus desarrollado por este autor ${ }^{19}$.

Por último, entender constructivamente el aporte de la antropología literaria pasaría por comprender que ella, al establecer un vínculo peculiar entre antropología y literatura, está contribuyendo a esclarecer el problema de la definición de "lo intercultural". En este sentido, cabe destacar que el gran problema de "lo intercultural" sigue siendo su definición, es decir: ¿Desde dónde se debe/puede hablar de interculturalidad? Es ineludiblemente necesario preguntarnos y precisar desde dónde hemos hablado acerca de lo intercultural; pero, también, desde dónde deberíamos hablar. Es decir, cuestionarnos: ¿Dónde deberíamos estar?, ¿cuál sería la situación de interlocución más adecuada para dar cuenta eficazmente de este tema? De este modo, se puede visualizar que construir un discurso de lo intercultural desde la filosofía, las humanidades y las ciencias sociales actuales, necesariamente implica realizar una redescripción de estos ámbitos, la cual conlleve a una práctica dialógica y polifónica, constitutiva de su quehacer mismo.

Cabe rescatar al respecto los estudios del filósofo cubano Fornet-Betancourt, a través de los cuales señala que la búsqueda de una definición de lo intercultural se hace problemática, porque definir implica "delimitar y fijar", lo cual se realiza utilizando referentes teóricos que habitualmente se toman de alguna disciplina en la cual nos hemos formado o desde la que ejercemos como profesionales. En este sentido, si la definición de lo intercultural se realiza desde el hábito de ejercer la "observancia estricta de la división del saber", desde la práctica preocupada de establecer las fronteras exactas entre las disciplinas; entonces, se puede caer en un discurso monodisciplinar y monocultural de lo intercultural que implica, a su vez, un "costo intercultural” al reducir dicho fenómeno a mero "objeto” de estudio. Surge así la pregunta: ¿Cómo hablar de lo intercultural sin caer en un discurso monocultural? “...Esto significa que cualquier definición de lo intercultural debe hacerse cargo de su contextualidad, tanto cultural como disciplinar, y de presentarse no como la perspectiva que demarca los límites de lo que enfoca sino, por el contrario, como una ventana que permite ver sólo una parte del espacio abierto hacia el que da. De ahí la necesidad de la contrastación de las definiciones... (Fornet-Betancourt 2002) ${ }^{20}$.

Con respecto a este problema, más que el contraste de definiciones, en la escritura de Alvarado se reflejaría lo que Fornet-Betancourt señala como el aspecto principal de este proceso: su carácter experiencial y biográfico. Con ello, el contraste de las definiciones sería una práctica que no se reduce sólo al ámbito de teorías, enfoques elaborados o conceptos sobre lo intercultural. Por el contrario, como dice este filósofo: "este debate contrastante debe incluir además el nivel experiencial y biográfico" (Fornet-Betancourt 2002); niveles que se entrelazan en la antropología literaria. De hecho, en el texto de El espejo rápido se dan la mano antropología y literatura para llegar al desarrollo de una escritura entendida como un acto de solidaridad histórica. De este modo, la literatura que está presente en la antropología de Alvarado puede ser entendida como la experiencia de una relación entre: escritor, sociedad, historia y emotividad; interconexión expresada en una "escritura densa" que intenta rescatar la mirada divergente de los distintos actores implicados. Sería, entonces, una escritura comprometida que refleja los problemas del ser humano y de la sociedad, utilizando como código fundamental la extrañeza y la plurisignificación. Además, podría agregarse que, para Alvarado, el autor es siempre colectivo, ya que la obra se transmite a lo largo del tiempo y cada persona-lector/a aporta algo a la obra. De este modo, se daría en la antropología literaria un cruce activo entre el antropólogo como autor, los personajes-nativos interpretados e interpretantes y el lector cómplice. Me atrevería a decir que se daría una especie de coautoría, al menos entre antropólogo e informantes; una coautoría que sería ineludible al momento de definir lo intercultural y al instante de abordar los problemas humanos desde esta perspectiva. En este sentido, Alvarado dice: “... es fundamental que el "otro"

\footnotetext{
19 Alvarado señala respecto del concepto de habitus: "Esa libertad concertada en el concepto de habitus es entendida como una 'estructura estructurante', es decir, como un marco con límites flexibles que posee una suerte de gramática cultural unida a una posibilidad de juego o movimiento, con lo cual el habitus se sostendría como una entidad dinámica capaz de dar dinámicamente respuesta a la necesidad del cambio cultural y operar en los campos o esferas de la realidad" (Alvarado 2006: 104).

${ }^{20}$ Este autor enfatiza que: “...habría que comenzar por preguntar no por la definición que podemos dar de lo intercultural, sino más bien por los recursos culturales y conceptuales de que disponemos para nuestras definiciones. Preguntarnos, por ejemplo, si nuestra manera de pensar es ya tal que nos permite una aproximación intercultural a la realidad de la interculturalidad" (Fornet-Betancourt 2002. "Lo intercultural: El problema de y con su definición”, Revista Pasos. 103. San José, Costa Rica: Departamento Ecuménico de Investigaciones (DEI). Disponible en Internet.)
} 
tenga la posibilidad de hacer escuchar 'su voz' en el texto, sin represiones o limitaciones impuestas por el etnógrafo" (2006: 156).

\section{PARA SEGUIR DIALOGANDO CON LA ANTROPOLOGÍA LITERARIA: LA CRÍTICA, EL SILENCIO O, AL MENOS, UNA INTERROGANTE}

Llega el momento de aportar con una crítica y de enfrentar la pregunta: ¿Desde dónde criticar un libro fragmentario y sugerente, una escritura con alma bella ${ }^{21}$, pero terrible? Una crítica sugerente hacia la antropología literaria que aparece en el libro El espejo rápido se podría articular desde el deseo de un lenguaje nuevo para las ciencias humanas. Sin embargo, el deseo de guardar silencio aparece y reaparece en la trayectoria misma de la crítica posible, porque, en definitiva, esta forma de escritura hace enmudecer, pues con su lectura tomamos conciencia de los propios límites. No obstante, simultáneamente se deja sentir el deseo de una comprensión más profunda y, entonces, surgen algunas interrogantes que se logran articular con la esperanza de lograr una perspectiva alternativa que supere tanto una mirada positivista, obsesionada con el orden y las definiciones, como una postura nihilista, que se obsesiona con el desorden y la indefinición.

En este sentido cabe señalar la ausencia en El espejo rápido de una interpretación del vocablo que reiteradamente aparece en distintos pasajes del libro: la palabra ambigüedad. Una lectura científica convencional castiga a esta palabra y por ello es deseable contar con una interpretación explícita y constructiva de este término y de sus implicancias en los tres planos mencionados anteriormente: interrelación cuerpo-lenguaje; indisciplinamiento de las ciencias sociales y definición de lo intercultural.

Al respecto, sólo como una primera aproximación, es necesario señalar que esta ambigüedad, entendida como una propiedad del lenguaje, no remite sólo a la idea de algo puramente "dudoso" sino también de algo "sugerente". Permite enriquecer el lenguaje de las ciencias humanas y humanidades, especialmente de aquellas que se apoyan en una antropología filosófica y hermenéutica que rescata el aspecto constitutivo del ser humano como "agente corpóreo y dialógico". De este modo, con una connotación positiva del concepto de ambigüedad se abren para el mundo de las ciencias humanas algunas posibilidades de comprensión más profunda y esclarecedora del significado de "lo inter"; de lo que aparece cuando nos situamos en ese espacio ambiguo que configuramos al estar "entre culturas" y "entre disciplinas". En este sentido, el reconocimiento por parte del mundo de la ciencia de que ella misma está inserta en otro mundo: el mundo de la vida, en donde la riqueza y la complejidad de la vida humana transcurre a través de relatos y microhistorias humanas, las cuales están constituidas por una ambigüedad que tiene relación con el hecho de que una misma palabra, oración o frase admite dos o más significados distintos; todo ello conllevaría necesariamente al desarrollo de unas ciencias contextuales y expresivas que requieren asumir, ineludiblemente, que los juegos de lenguaje cotidianos constituyen una dinámica ambigua, lo cual se desarrolla desde de la ambigüedad de nuestra existencia corpórea y que se expresa en emociones, sensaciones y sentimientos que exigen una expresión a través de una palabra viviente.

En el caso de la escritura de la antropología literaria, su carácter revela una predilección por plasmar las vivencias a través de juegos de lenguaje necesariamente ambiguos, porque uno de sus objetivos sería sugerir la simultánea heterogeneidad: sugerir caminos que lleven a otros caminos; sugerir historias que contienen otras historias; sugerir distintas vidas dentro de una vida. En este sentido, la antropología literaria en su búsqueda de lo intercultural establecería, por ejemplo, un diálogo con el estudio crítico de la literatura, especialmente en nuestro caso, con el estudio de la literatura mapuche, como ya se ha señalado a propósito de las investigaciones de Iván Carrasco. Este diálogo podría enriquecer los procesos de generación de conocimiento de las ciencias humanas desde contextos de diversidad cultural si, por ejemplo, se busca una articulación entre la idea de unidades significativas multifacéticas que permite al pueblo mapuche articular libre y espontáneamente una cosmovisión en términos mítico-religiosos e históricos (Carrasco I. 1972) ${ }^{22}$ y la idea de cuerpos interpretantes que sugiere Alvarado para superar

\footnotetext{
${ }^{21}$ El concepto de alma bella seleccionado para caracterizar a la antropología literaria y su escritura, se asume de acuerdo al significado que tiene en la filosofía del joven Hegel. Este filósofo, en sus Escritos de juventud, nos dice que un alma bella asume la conflictividad de la vida y sin renunciar a ella asume su destino: no se somete a él, sino que lo hace suyo. Sólo alguien pleno de amor puede manifestarse tan libremente, sin buscar provecho alguno para su acción. Véase: Cárcamo, S. 2004. "El concepto de amor en el joven Hegel: Una experiencia de reconciliación de la vida consigo misma". Trabajo de investigación para el curso Existencia y Libertad, Doctorado en Filosofía, Lógica y Estética, Universidad de Salamanca. España.
}

22 Antecedentes para esta posible articulación ya han sido formulados por Iván Carrasco, quien ya nos ha sugerido transformar la pregunta: “¿es necesario el conocimiento de la literatura del pueblo mapuche, se justifica su estudio, tiene sentido dedicar tiempo y 
nuestros dilemas por el sustrato empírico ${ }^{23}$.

Con respecto a la vocación interdisciplinaria de la antropología literaria cabe la duda si, efectivamente, desea convocar a otras disciplinas en este proyecto de un lenguaje y de un metalenguaje nuevos en las humanidades o, más bien, es una invitación directa para antropólogos y estudiosos del lenguaje e indirecta para el resto de las humanidades. Si bien el autor habla de una invitación abierta y no excluyente; la lectura, especialmente de las cartas que aparecen en el libro, más bien sugiere que se trataría de un proyecto que busca rearticular un lenguaje expresivo desde la etnografía. Este aspecto no está abiertamente esclarecido, porque algunos estudios, especialmente los que aparecen en el capítulo: "Otra ciencia otra narración", y algunos del capítulo: "Aportes a la narración: lenguaje, estructura, conflicto y autonomía" (cuando habla, por ejemplo, de Goffman, Schutz y Bourdieu) parecen tener, más bien, una intencionalidad metadiscursiva. Entonces, la pregunta que surge es: ¿La antropología literaria busca constituirse en un nuevo lenguaje en ciencias humanas desde la antropología, en diálogo con la filosofía del lenguaje y la estética o busca articular un metalenguaje en ciencias humanas desde distintos ámbitos disciplinarios y extradisciplinarios? ¿O ambas cosas a la vez?

Otra pregunta, vinculada a la anterior, es ¿cómo se sitúa la antropología literaria frente a las ciencias humanas? ¿Su postura es de una ruptura radical y alternativa con respecto a las prácticas científicosociales actuales, todo ello por la vía de la superación de las deficiencias de los límites disciplinarios? En definitiva, la pregunta también podría formularse diciendo: ¿cómo la antropología literaria entiende a las ciencias humanas y su desarrollo? ¿Quiere seguir hablando de ciencias humanas o preferiría hablar de humanidades?

Finalmente, frente a la temática de lo intercultural, la antropología literaria asume la complejidad del encuentro entre culturas y, entonces: $¿$ Su escritura buscaría intencionalmente intensificar los contrastes de lenguaje para hacer más visible el valor y riqueza de la diversidad o pretende ir más allá y buscar, desde ese contraste, la traducción recíproca?

\section{CONCLUSIÓN}

Para quien estudia las ciencias humanas y no encuentra satisfacción en unas enseñanzas descontextualizadas que, sin embargo, ya ha asimilado a medias; para quien a tropezones descubre retazos de teorías alternativas que sugieren la existencia de hombres y mujeres de "carne y hueso", teorías que aparecen en algún rincón de un laberinto de provincia; para un/a estudioso/a de esta estirpe, es difícil, arduo, complejo, pero ineludiblemente necesario hablar de antropología literaria. Aunque su estudio asfixie, parece ser uno de los pocos caminos que llevan a un puerto que salva del malestar cultural de la escisión interior y del atomismo social.

Desde esta perspectiva, es deseable que la antropología literaria participe activamente en la comunidad de científicos sociales como una hermenéutica crítica intercultural que busca redescubrir el concepto de humanidades desde una epistemología fronteriza, desde unos saberes que han sido silenciados y olvidados. Para su validación frente a las disciplinas sociales convencionales es necesario que la antropología literaria asuma un lenguaje de contraste que, sin traicionar su ethos expresivo, nos diga cómo se plantea frente a las concepciones y prácticas dominantes de la gnoseología, la epistemología y la metodología. Entonces, sigue vigente la pregunta: ¿Cómo se inscribe o se sitúa la antropología literaria frente a la antropología, la literatura y frente a otras ciencias humanas y humanidades, en general? Si se asume que nuestra forma de vida actual es intelectualmente corrupta porque es una amalgama de dos visiones erróneas y excluyentes, el cientificismo (objetivismo) más craso que se mezcla con las formas más subjetivistas de expresivismo (Taylor 2005), entonces, la antropología literaria podría ser presentada como un metadiscurso humanista de las ciencias humanas

esfuerzo a ello?" en otra interrogante que tiene relación con la concepción de la literatura como "signo de la historia de un pueblo". La pregunta se expresaría, entonces, de este modo: “¿es necesario el conocimiento del pueblo mapuche a través de su literatura, y hasta dónde esto es posible?... De lo cual surge otra interrogante: ¿puede hacer un aporte valiosos a las ciencias humanas el estudio científico de la literatura de los pueblos para su conocimiento, o este estudio deberá realizarse únicamente a través de otras disciplinas, como la antropología, la historia, la sicología o la sociología?... Creo que la adecuada respuesta a esta pregunta es de cierto interés, no sólo para el desarrollo pleno de la ciencia actual, sino para el conocimiento objetivo y completo de la cultura humana" (Carrasco I. 1972: 17).

${ }^{23} \mathrm{Al}$ respecto, Alvarado señala: "La verdad del cuerpo es la verdad de la circunstancia dicha (...) de otra forma el cuerpo es un laberinto roto (...) y realmente por malo o bueno que sea vivir nuestro cuerpo no salimos de él nunca verdaderamente, lo que rodea al laberinto más allá del cuerpo es una maraña que como occidentales difícilmente reconocemos y menos aún controlamos" (2007: 17). 
que supere el subjetivismo en el descubrimiento y la articulación de lo expresado, que evite una concepción subjetivista de la experiencia que la transforma en un sentimentalismo informe y que haga una fuerte crítica al cientificismo y sus explicaciones reduccionistas de la vida humana.

Para situarnos en el "entre/inter", resulta ineludiblemente necesario asumir como un destino la forma de ser, de estar, de decir y de escribir, que propone la antropología literaria. En este sentido, nos ayudaría una metáfora que nos diga que somos visitantes, peregrinos, siempre en tránsito y que, por ello, es necesario caminar entre disciplinas, entre culturas, estableciendo lazos entre el cuerpo y el lenguaje. Transitar entre antropología y literatura como un caminante que entre la niebla de la noche sólo vislumbra la luz tenue de un farol y decide construir un camino o un puente para llegar a él.

\section{OBRAS CITADAS}

Alvarado, Miguel. 2004. El sueño de la comunicación. Aportes sobre narración y diversidad en el contexto latinoamericano. Valparaíso: Universidad de Playa Ancha. Programa de Estudios de la Diversidad Sociocultural "Ricardo Latcham".

2006. El espejo rápido. Interculturalidad y Prevaricaciones Discursivas. Valparaíso: Editorial Puntángeles, Universidad de Playa Ancha; incl. Sergio Vuskovic, "Los remolinos en la cultura chilena", 11-2; "A la manera de un prólogo", Sonia Montecino, 13-5; "Prólogo", Raúl Zurita, 17-9.

—. 2007. "La antropología literaria y su dilema por el sustrato empírico". La Torre del Virrey. Revista de Estudios Culturales 4.

Brunner, José Joaquín. 1997. "Sobre el Crepúsculo de la Sociología y el Comienzo de otras Narrativas". Ponencia en celebración del $40^{\circ}$ aniversario de FLACSO.

Cárcamo, Solange. 2004. "El concepto de amor en el joven Hegel: Una experiencia de reconciliación de la vida consigo misma". Trabajo de investigación para el curso Existencia y Libertad, Doctorado en Filosofía, Lógica y Estética, Universidad de Salamanca. España.

Carrasco, Iván. 1972. "Notas introductorias a la literatura mapuche". Tercera semana indigenista. Temuco: Ediciones Universitarias de la Frontera.

Castro-Gómez, Schiwy y Walsh. 2002. Indisciplinar las ciencias sociales. Geopolíticas del conocimiento y colonialidad del poder: Perspectivas desde lo andino. Quito: Universidad Andina Simón Bolívar/AbyaYala.

Castro-Gómez, S y Mendieta (eds.). México. Teorías sin disciplina (latinoamericanismo, poscolonialidad y globalización en debate). Disponible en: http://www.ensayistas.org/crítica/teoría/castro/mignolo.htm

Fornet-Betancourt, Raúl. 2002. "Lo intercultural: El problema de y con su definición”. Revista Pasos 103. Costa Rica, San José, Costa Rica: Departamento Ecuménico de Investigaciones (DEI).

Gómez y Mendieta (eds.). México. Teorías sin disciplina (latinoamericanismo, poscolonialidad y globalización en debate). Disponible en: http://www.ensayistas.org/crítica/teoría/castro/mignolo.htm.

Grondin, Jean. 2003. Introducción a Gadamer. Barcelona: Herder.

López-Baralt, Mercedes. 2005. Para decir al Otro. Lliteratura y antropología en nuestra América. Madrid: Iberoamericana - Vervuert.

Merleau-Ponty. 1957. Fenomenología de la percepción. México: FCE.

Mignolo, W. D. (s.f.) "Espacios geográficos y localizaciones epistemológicas: La ratio entre la localización geográfica y la subalternización de conocimientos". http://www.javeriana.edu.co/pensar/Rev3.html.

—_ 1998 "Postoccidentalismo: el argumento desde América Latina". En Castro-Gómez S. y Mendieta...

Morandé, Pedro. 2006. "Presentación del libro: "El espejo rápido. Interculturalidad y prevaricaciones discursivas" de Miguel Alvarado Borgoño. Valparaíso, Universidad de Playa Ancha.

Paredes Martín, Ma del Carmen. 1999. "Cuerpo y sujeto", Daivmwn Revista de Filosofía 18, Enero-Junio, Universidad de Murcia.

Taylor, Charles. 1993. Multiculturalismo y la política del reconocimiento. México: F.C.E.

—. 2005. La Libertad de los modernos. Madrid: Amorrortu Editores.

Verano, Leonardo. 2000. "Cuerpo y lenguaje. Una aproximación a la fenomenología de Merleau-Ponty". La

Fenomenología en América Latina. Bogotá: Universidad de San Buenaventura, Serie de Filosofía 3. 